\title{
Current Teaching Practice of Physics Teachers and Implications for Integrated Stem Education
}

\author{
Muhammad Abd Hadi Bunyamin ${ }^{1, *}$, Corrienna Abdul Talib ${ }^{1}$, Nur Jahan Ahmad², \\ Nor Hasniza Ibrahim ${ }^{1}$, Johari Surif ${ }^{1}$ \\ ${ }^{1}$ School of Education, Faculty of Social Sciences and Humanities, Universiti Teknologi Malaysia, Malaysia \\ ${ }^{2}$ School of Educational Studies, Universiti Sains Malaysia, Malaysia
}

Received January 22, 2020; Revised April 1, 2020; Accepted April 21, 2020

Copyright $\mathrm{C} 2020$ by authors, all rights reserved. Authors agree that this article remains permanently open access under the terms of the Creative Commons Attribution License 4.0 International License

\begin{abstract}
Physics teaching practice is important to be studied because the literature shows that physics has a close connection with the idea of integrated science, technology, engineering and mathematics (STEM). Understanding physics teaching would likely show many features of integrated STEM teaching. However, this assumption needs to be researched. Thus, this study aims to characterize the current practice of teaching of physics to inform the future implementation of integrated STEM teaching. A qualitative research design was adopted. Three physics teachers were purposefully selected because of their background in STEM education. Classroom observations, semi-structured interviews and documents were used to gather data on usual teachers' practice of teaching physics. The modified version of integrated STEM teaching framework was used to guide the data analysis. In-depth descriptions on teachers' teaching practice are provided. This study found that the physics teachers' teaching practice did not align with their thoughts on integrated STEM teaching. However, they relatively had precise conceptions of integrated STEM teaching. Support should be given to physics teachers to translate their conceptions of integrated STEM teaching into actual classroom teaching practice.
\end{abstract}

Keywords Integrated STEM Teaching, Teaching Practice, Physics Teachers, Qualitative Approach

\section{Introduction}

The Malaysian Ministry of Education (MOE) (2013) has expressed an interest in enhancing science, technology, engineering and mathematics (STEM) education. Many initiatives have been undertaken to reform STEM education such as the introduction of a new science curriculum for secondary schools in 2017 and school-based assessment in 2011. All of these efforts are aimed to transform STEM education to place Malaysian schools in the global education landscape.

Nonetheless, the word of "STEM" has many perspectives. Bybee (2013) has described nine perspectives of STEM. Some of them are: (1) STEM means science and incorporates technology, engineering, or mathematics, (2) STEM means both science and mathematics, (3) STEM equals science (or mathematics), (4) STEM equals a quartet of separate disciplines, (5) STEM is a new discipline (transdisciplinary). Each of the STEM perspective is either single-based discipline or multiple-based. For example, the perspective of STEM equals a quartet of separate disciplines is a single-based perspective while STEM means both science and mathematics is multiple-based. Recent studies have found that teachers now tend to adopt integrated STEM education but with different degrees of integration (Kloser, Wilsey, Twohy, Immonen, \& Navotas, 2018; Srikoom, Hanuscin, \& Faikhamta, 2017).

In the STEM education literature, the preferred perspective of STEM is integrated STEM (Bryan, Moore, Johnson, \& Roehrig, 2016). It is a multiple-based discipline of STEM and is not simply teaching science with additions of other subjects. Bryan et al. (2013) has defined integrated STEM as "the teaching and learning of the content and practices of disciplinary knowledge which include science and/or mathematics through the integration of the practices of engineering and engineering design of relevant technologies" (pp. 23-24). Additionally, Bryan et al. have mentioned that STEM practices and skills in integrated STEM teaching cover scientific inquiry, engineering and engineering design, and mathematical thinking and reasoning. 
Many studies have used physics as the primary subject of research on integrated STEM. For example, Kim et al. (2015) have used the topic of Robotic in researching STEM teaching. Other researchers have used the topics of force and motion (Kertil \& Gurel, 2016). All of these topics are physics and physics-related. Roehrig et al. (2012) has suggested that physical science has a natural connection with engineering. Roehrig el al.'s claim is true even though they did not provide in-depth explanations about the claim. From this scenario, physics teaching might be the most probable platform for scholars to capture integrated STEM elements than the other subjects' teaching such as chemistry and biology.

However, many studies have found that implementing integrated STEM teaching is challenging (Czerniak \& Johnson, 2014; Stohlmann et al., 2011; Wang, 2012). In general, the challenges are that many science teachers were not trained to use integrated STEM during the pre-service teacher education programs and they have insufficient knowledge in integrated STEM teaching (Siew et al., 2015). These problems impede effective teaching of integrated STEM.

Another issue is that many researches in STEM education have been conducted in higher education settings (Jayarajah, Saat, \& Rauf, 2014). The finding from Jayarajah et al.'s review is not surprising because universities can offer many STEM courses that are transdisciplinary unlike schools. School settings are totally different from the universities' because schools' systems are more standardized than universities' hence schools cannot offer many courses created by themselves unlike the universities. This explanation might be best to respond to Jayarajah et al.'s review.

From this scenario, the researchers of this study deem that researching physics teachers' teaching in schools would be the best option to see how physics teachers teach in actual classrooms. Considering that integrated STEM is not well established in Malaysia and is quite new for many science and physics teachers, the researchers want to characterize the physics teachers' current teaching practices to inform the way forward to implementing integrated STEM in the future.

The significance of this study is that the results regarding analysis of the physics teachers' current teaching practices would expose the specific elements of integrated STEM that are available and not. From the analysis, recommendations would be made to improve and enhance teaching of physics using the concept of integrated STEM as the framework of referenced. The results might be transferable to other subjects such as chemistry and biology when appropriate. Recognizing that STEM education researches are not common in school settings, this study would also contribute to the literature in school STEM education.

\section{Objective and Research Questions}

This study aims to characterize the current practice of teaching of physics to inform the future implementation of integrated STEM teaching. The research question is: what is the current teaching practice of physics in actual classrooms in relation to integrated STEM teaching practice?

\section{Literature Review}

This review of literature covers the debates of STEM perspectives, studies on physics teaching in relation to integrated STEM, studies on physics teaching, and the conceptual framework of this study. All these three are important to inform readers about the reality of diverse perspectives on STEM, the connection of physics with STEM and the main approach of teaching physics, and the framework that has guided this study.

\subsection{Multiple Perspectives on STEM}

The literature has shown that STEM has no single perspective. Many perspectives on STEM are available (Bybee, 2013). Bybee has described nine perspectives on STEM (pp. 74-79). The nine have indicated that STEM may be either single-based discipline or multiple-based. For instance, Bybee mentioned about the perspective on STEM that equals a quartet of separate disciplines, science, technology, engineering, and mathematics (pp. 76). It means each of the four STEM discipline is silo and may include four separate courses. On the other hand, one example of the multiple-based discipline is STEM as a transdisciplinary course or program (pp. 78). It means the elements of science, technology, engineering, and mathematics are all integrated to produce a new course such as Smart City that requires use of all STEM disciplines. From the nine perspectives, only two are single-based discipline while others are multiple-based. This shows that the perspectives on STEM are mostly multiple-discipline.

Should STEM be single- or multiple-discipline? Czerniak and Johnson (2014) have conducted a review on interdisciplinary science teaching (pp. 395-411). It shows that the debates of teaching science of either single- or multiple-discipline have been happening for more than a hundred years (pp. 396). Thus, the debates are not new. However, the important thing is to know that few empirical studies have supported the assertion that integrated STEM teaching is more effective than the single-discipline or traditional teaching (pp. 398). The result of Czerniak and Johnson's review has implied that implementation of integrated STEM teaching might not always be the choice for teaching in practice. Lacks of evidence to say that 
integrated STEM teaching is effective provide a critical question, is it necessary for all physics teachers to adopt this approach?

The researchers of this study (we) deem that the necessity of adopting integrated STEM is varied across teachers. One teacher may take up the approach while others may not, depending on what he or she can do. In this regard, levels of implementation of STEM would be expected. Bybee's descriptions on various STEM perspectives are referenced. In terms of implementation, and even the planning or thinking of teaching, not all teachers may reach the highest level of integrated STEM, the $9^{\text {th }}$ perspective (Bybee, 2013, pp. 79). The reason is that each teacher may have different conceptions of STEM and thus their teaching practices are diverse. We do not hold the paradigm of postpositivism that tends to "standardize" STEM teaching and meaning. Instead, we want to see how physics teachers teach topics of physics in relation to their thoughts regarding STEM and see the multiple realities of teaching physics which are the paradigm of an interpretivist.

\subsection{Physics and STEM}

Many studies on STEM have been carried out. Excitingly, the topics used as the subject of research are mostly physics and physics-related. For instance, Kertil and Gurel (2016) have made a theoretical discussion regarding the connection between integrated STEM and mathematical modelling. In their discussion, they used an example of a project-based learning as an example of integrated STEM education. Excitingly, they put a model of rocketry project as the specific example, which is closely related to physics. Designing a rocket requires applications of physics concepts such as Newton laws, impulse, and momentum. Kertil and Gurel have mentioned about these physics concepts in their writing.

The second example is a study by Kim et al. (2015). Kim et al. have used robotics as the subject of research. They studied about pre-service teachers' STEM engagement, learning, and teaching through robotics using multiple data sources, surveys, classroom observations, interviews, and lesson plans. The reasons for selecting robotics are that it enables students to apply concepts of engineering and technology and to make science and mathematics more concrete than abstract. However, Kim et al.'s did not explicitly mention about the good fit between physics and STEM.

The two studies described imply that physics might be the subject that has the best fit with integrated STEM elements. Other studies (Siew et al., 2015; Roehrig, et al. 2012) have also used topics that have many physics elements. Thus, selecting the physics subject is appropriate and is most likely to show elements of integrated STEM (Bunyamin \& Finley, 2016).

\subsection{Studies on Physics Teaching}

Duit, Schecker, Hottecke, and Niedderer (2014) have made a review on physics teaching. In the review, they identified practical work as one research area that is popular in physics education research. Practical work is vital for physics classes. Teachers usually ask students to do experiments with some guides from teachers' demonstrations. However, many physics teachers strictly guide their students for doing the experiments, meanwhile students conduct lab work using step-by-step procedures mentioned in lab manuals. For this reason, Hofstein and Kind (2012) stated that doing lab work is mostly about manipulating materials and apparatuses, but not ideas.

According to the national physics curriculum (Ministry of Education, 2005), doing experiments or lab work is recommended. Teachers are suggested to ask students to conduct investigations such as buoyancy, atmospheric pressure, gas pressure, and momentum. In fact, the Paper 3 of the national physics examination asks students to plan for a scientific investigation of a given phenomenon.

In relation to integrated STEM, scientific inquiry is one of STEM practices along with engineering design and mathematical thinking (Bryan et al., 2016). This suggests that integrated STEM is not just about engineering design. Scientific inquiry is still valuable and useful for students to learn physics using concrete materials. Without conducting scientific investigations, students might not be able to "see" physics in tangible manners. For this reason, this study covers engineering design and scientific inquiry as two STEM practices for physics.

\subsection{The Conceptual Framework}

The researchers have deemed that the studies and writing by Bybee (2013), Czerniak and Johnson (2014), Bryan et al. (2016), Kertil and Gurel (2016), Kim et al. (2015), Moore et al. (2016), etc. are useful and informative. From their studies, the researchers use the framework of integrated STEM by Moore et al. (2016) with minor modifications. The minor is the second construct regarding engineering design. The framework covers:

(1) Integration of science and mathematics

(2) Use of engineering design and/or scientific inquiry and redesigning/reinvestigating activities for a better student learning

(3) Inclusion of real-world contexts

(4) Use of student-centred approaches

(5) Communication and teamwork among students

The primary intention for using the framework is not to assess physics teachers' teaching, but is to characterize elements of integrated STEM available in the teachers' current practice of teaching physics. This study did not want to judge the teachers' teaching, but to identify elements of integrated STEM that could be strengthened, continued, or added for future teaching of physics. 


\section{Methodology}

The authors adopted an interpretive paradigm for this study. We acknowledged diverse teaching practices of physics teachers and STEM conceptions and tried to understand them. Thus, a qualitative design was appropriate to answer the research questions that were subjective in nature.

Three physics teachers were selected using the purposeful sampling method (Creswell, 2013). Three participants were sufficient because a qualitative study usually involves a small number of participants in order to get in-depth data. The main criteria for the selection of participants were: (1) they all taught physics, (2) they had STEM or STEM-related backgrounds and (3) they must have an academic qualification in physics education. All of these criteria were important to ensure that they were confident to teach physics with sufficient knowledge and skills and also would be able to convey about STEM teaching.

The first teacher was Yusof (not real name) who is a male physics teacher and has been teaching physics since 2009. His current school is located in Johor, Malaysia and is a high performing school. In 2015, he brought a group of students to compete in an international competition of scientific innovations in South Korea, which was related to STEM education. It was a great achievement for him as the mentor of the group. Yusof possesses a master's degree in physics education and a bachelor's degree in the same field.

The second teacher was Aliah. Aliah is a female physics teacher who has a status of an excellent physics teacher, awarded by the MOE in 2015. That status was the reason for her selection because she would be able to convey about excellent physics teaching and would be able to relate it with STEM teaching. She has been teaching physics since 2007. Her current school is located in a suburban area in Johor and has shown potential to be an excellent school in the future. Aliah has a bachelor's degree in physics education.

The third teacher was Maryam. Maryam is a female physics teacher. She has a role in managing international assessment tasks by her school. The international assessments, which were the Program for International Student Assessment (PISA) and the Trends in the International Mathematics and Science Study (TIMSS), were related to STEM education. This role was the reason for her selection. She has been teaching physics since 2010 . Her school is located in a suburban area in Johor and has a vision to be an excellent school. Maryam possesses a bachelor's degree in physics education.

This study was carried out from $1^{\text {st }}$ July 12015 to $2^{\text {nd }}$ September 2015. To get data, we conducted individual semi-structured interviews (Rubin \& Rubin, 2012), made classroom teaching observations (Patton, 2002), and collected documents related to the topics taught.
First, we conducted individual pre-teaching interviews for all teachers to get data on the teachers' preferences of teaching, goals of teaching, and their usual teaching practices. The interviews were around 60 to 70 minutes and were recorded and transcribed. Some of the main questions asked were: (1) what are the goals of your physics teaching? (2) how do you usually teach physics? and (3) what are the reasons for using particular teaching approaches? These main questions were asked to all the physics teachers.

Then, we made classroom teaching observations for six topics of physics: pressure, pressure in liquid, atmospheric and gas pressure, Pascal's principle, Archimedes' principle and Bernoulli's principle (Ministry of Education, 2005). The aim was to get data on the teachers' actual classroom teaching practices as a way to validate data from interviews. Seven observations were made for Yusof, six for Aliah, and eight for Maryam. The numbers of observations were different because each teacher taught based on her or his personal plan of teaching. The observations were recorded using a voice recorder given to the teachers and were transcribed. When observing the teachers, the principal researcher took free notes of the teachers' approaches of teaching to inform construction of the post-teaching interview questions as well as to help the data analysis process. The principal researcher also took several pictures of learning materials and products to enrich observation notes.

After completing the classroom teaching observations, individual post-teaching interviews were conducted. The interview was about the teachers' conceptions of STEM teaching. Some of the main questions asked were: (1) how do you conceptualize STEM teaching? and (2) what would be the reasons for using STEM teaching approaches? These main questions were asked to all the physics teachers. The interview was conducted around 40 minutes for each teacher.

Finally, documents such as lesson plans, teaching slides and written questions given by the teachers to students were collected. These documents were important to strengthen the interview and observation data. The teaching slides and written questions used were mostly from commercial companies that provided the teachers and schools with useful learning materials.

When transcriptions of classroom teaching observation recording and interviewing were completed, we referred to the guiding framework of Moore et al. (2016) regarding integrated STEM teaching to frame the data analysis process. First, we set initial codes for each teacher in each data source. For example, we created codes of "teacher-driven questioning" and "lecture" in the observation transcriptions, "dam" and "shoes" in the teaching slides and "integration of science, technology, engineering and mathematics" in the interview transcriptions for Yusof. This was called within case analysis (Saldana, 2013).

Then, cross-case analysis was conducted. Initial codes of 
each teacher were grouped into five categories. These categories were formed from the framework of integrated STEM by Moore et al. (2016) with minor changes: (1) integration of science and mathematics, (2) use of engineering design and/or scientific inquiry and redesigning/reinvestigating activities for a better student learning, (3) inclusion of real-world contexts, (4) use of student-centred pedagogy and (5) communication and teamwork among students. In-depth descriptions on the teachers' teaching practice of physics are provided to reveal the real practice of teaching as the means to extract integrated STEM teaching features. To ensure accuracy of the descriptions, the researchers contacted the three teachers for the member checking process (Merriam, 1998) where the teachers checked the descriptions made. Minor revisions were made accordingly.

Data triangulation was carried out to strengthen the findings. Data from pre- and post-teaching interviews were compared with observation data. The similarities of findings across data sources indicated a strong finding. For example, when Aliah was teaching pressure in liquid, she conducted a design activity (observation data). When she was interviewed, she explained the reasons for doing the activity. Photos of the activity were also taken to show that activity. Thus, observation data, interview data and document data were triangulated.

Finally, we came up with findings that answered the research questions. The main findings were produced when all teachers had a similar physics teaching practice and conception of STEM. However, findings that were unique for a teacher or two were also included to enrich the primary findings.

\section{Findings}

It is important to mention that this study is not intended to assess teachers' teaching of physics using integrated STEM framework. The real purpose is to characterize their current teaching practice and to see possible elements of STEM in their practice. The framework of integrated STEM is used as the ideal. Descriptions of the teachers' teaching practice are provided.

\subsection{Student-centred and Teacher-centred Pedagogy}

Across the three teachers, two teachers, Yusof and Maryam mostly used teacher-centred pedagogies when teaching all topics while Aliah frequently used student-centred ones. For Yusof, he primarily used the teacher-driven questioning method. One example of the questioning activity is when he was teaching the topic of Archimedes' principle:

Yusof: What are factors that affect the upward buoyant force?

Student $t_{1}$ : Density.
Yusof: Indeed.

Student 2 : The volume of an object.

Yusof: Yes. You just mentioned the density of liquid. If you use different types of liquids that means you have different densities. For instance, we can compare water and seawater. If we place the same apple into two those liquids, what difference can you note of the level of the apple?

Student 1 : The apple floats higher in seawater than fresh water.

Yusof: Yes, it does. It floats higher in seawater than fresh water. Then, see the volume of an object. The bigger the object, the bigger the buoyant force because its weight sustains the volume, right? The weight of the apples is equal to the buoyant force. We will see this idea after this. Hence, factors affecting the buoyant force are the volume of an object, the density of a liquid, and the gravitational acceleration.

[Data source: Voice records, 22 ${ }^{\text {nd }}$ July 2015]

In this type of questioning, Yusof asked questions, students answered them, and Yusof provided feedback to students' answers.

For Aliah, she mainly used student-centred pedagogies in many of the teaching activities especially when teaching the topics of pressure in liquid (design activities), atmospheric and gas pressure (student presentations) and Pascal's principle, Archimedes' principle and Bernoulli's principle (group discussion). For example, she implemented design activities when teaching the topic of pressure in liquid.

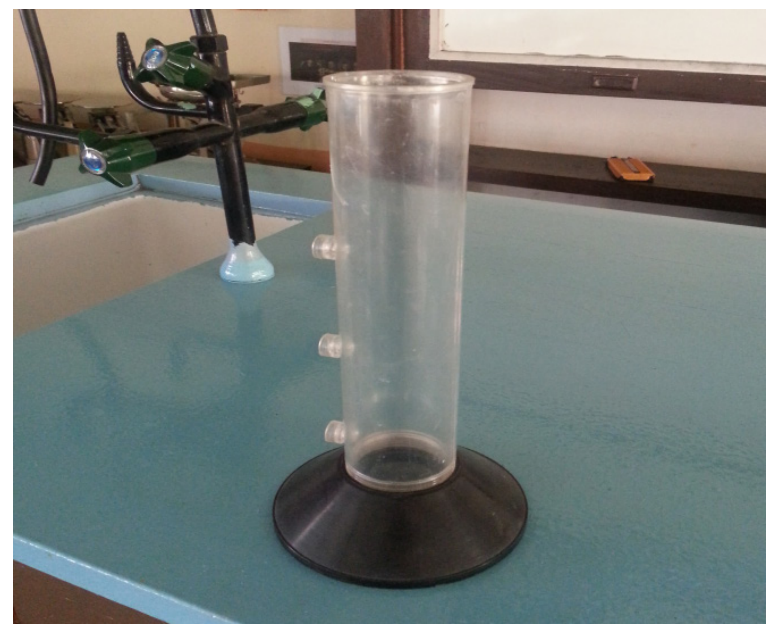

Figure 1. A Model to Understand Pressure in Liquid.

[Data source: Photos, $6^{\text {th }}$ July 2015]

Each table has bottles to do an activity to prove that pressure in liquid is influenced by height, $h$. The teacher demonstrated students a big cylinder (Figure 1) that was modified with some holes at different heights. She asked students to produce a similar model in groups. Bottles and hole makers were used to make holes at each bottle. 
This activity was a design activity. The teacher made a competition of the best model of pressure in liquid.

[Data source: Observation notes, $6^{\text {th }}$ July 2015]

For Maryam, she mainly used the teacher-driven questioning method when teaching all topics and she adopted a cookbook type of laboratory work when teaching Archimedes' principle. She asked students to do laboratory work according to her specific instructions and students needed to follow them. One example is provided, with a photo taken on the laboratory apparatuses settings in Figure 2.

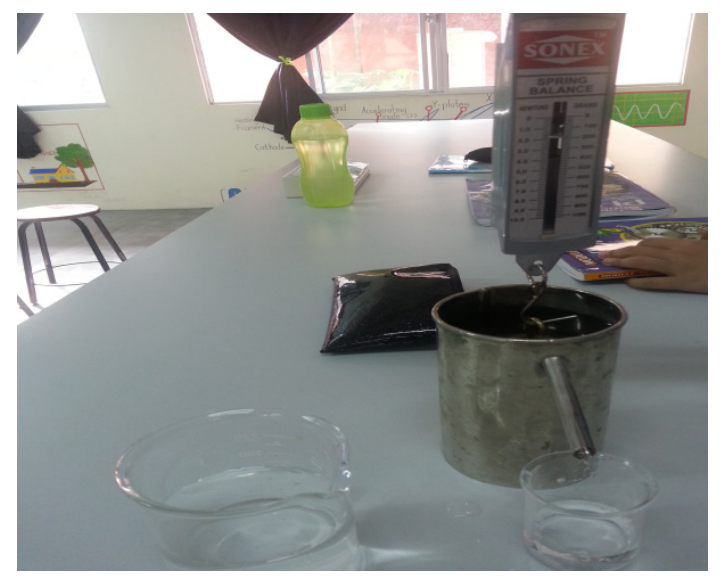

Figure 2. The Laboratory Work of Archimedes' Principle.

[Data source: Photos, $17^{\text {th }}$ August 2015]

Students were seen taking apparatus for a laboratory activity. The topic was Archimedes' principle. Each group had apparatus like spring balance, loads, and beakers. The teacher instructed the students to run the experiment step-by-step. The teacher interacted with students using questions to get students' ideas about Archimedes' principle. Each group was asked to give ideas why there was a difference in the reading of the weight of the load in water and in air. A group said that loss of the weight of the object was due to pressure in air and in water. Another group suggested that there was buoyant force.

[Data source: Observation notes, $17^{\text {th }}$ August 2015]

On the other hand, when interviewed, all teachers indicated that STEM teaching should be student-centred. They mentioned in the interviews that STEM teaching would give more opportunities for students to actively participate in the learning process, and teachers act as facilitators or do not totally control the learning process. For instance, Yusof mentioned that:

What I know about STEM is, it is science, technology, engineering and mathematics. STEM is a complete teaching approach where it involves mathematical calculations in teaching science and includes inventions or innovations to enhance technological use in the future. I feel that STEM is closely related to science subjects. I think that STEM teaching is student-centred where students control the learning process. Students need to question and generate new ideas while teachers do not dominate the learning process.

[Data source: Post-teaching interview, $26^{\text {th }}$ August 2015]

For Aliah, she stated that:

I have heard about the word of STEM. It emphasizes higher-order thinking and the twenty-first century skills and I imagine STEM as the use of science and mathematics into technological applications. I understand that STEM teaching should be student-centred using learning technologies. Probably we can see the use of robots in teaching in the future.

[Data source: Post-teaching interview, $22^{\text {nd }}$ August 2015]

For Maryam, she thought that, "STEM is the applications of science and mathematics in engineering and real-world applications. STEM teaching should be student-centred where students control the learning process and they might present their work more. Teachers are facilitators of students' learning" [Data source: Post-teaching interview, $2^{\text {nd }}$ September 2015].

Overall, the teachers' conceptions of STEM teaching seemed to have large contradictions with their usual teaching approaches, except for Aliah. However, they all appeared to have a relatively common conception of integrated STEM teaching: incorporating science with other STEM disciplines and use of student-centred pedagogies. These findings revealed that most of the teachers' typical approaches of teaching physics did not align with their views on integrated STEM teaching.

\subsection{Inclusion of Real-World Applications of Physics}

All of the teachers included real-world applications of the physics concepts taught. They all connected physical phenomena such as a floating ship or a boat with Archimedes' principle and a dam with pressure in liquid. Figures 3, 4 and 5 show the three teachers' slides of the topic of Archimedes' principle.

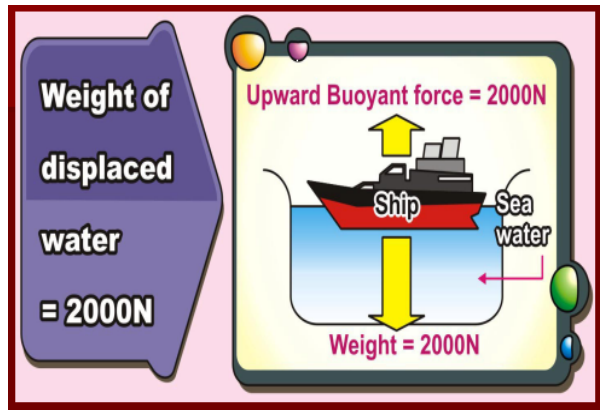

Figure 3. A Ship and the Buoyant Force.

[Data source: Yusof, $22^{\text {nd }}$ July 2015] 


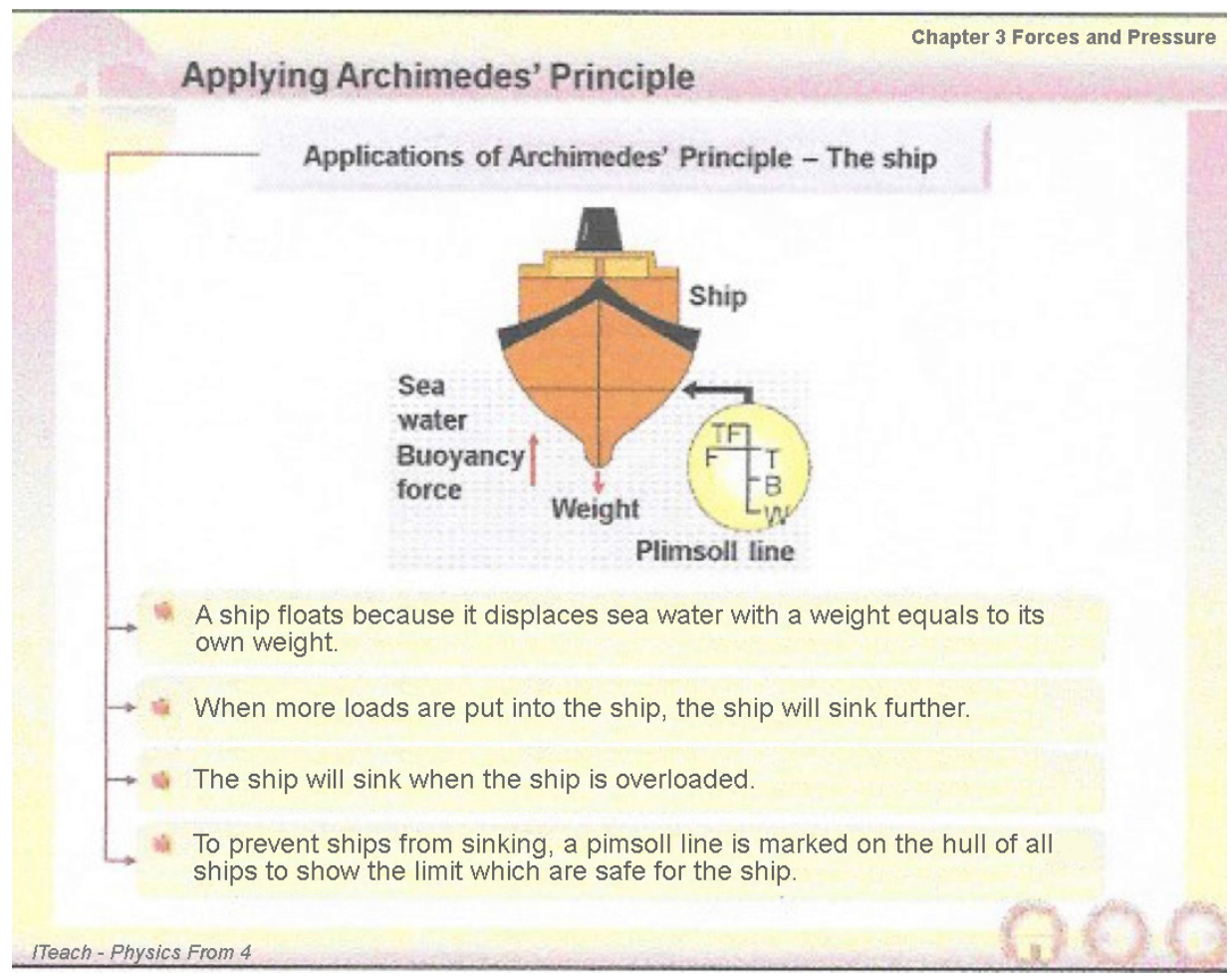

Figure 4. A Ship and the Buoyancy Application.

[Data source: Aliah, 27 $7^{\text {th }}$ July 2015]

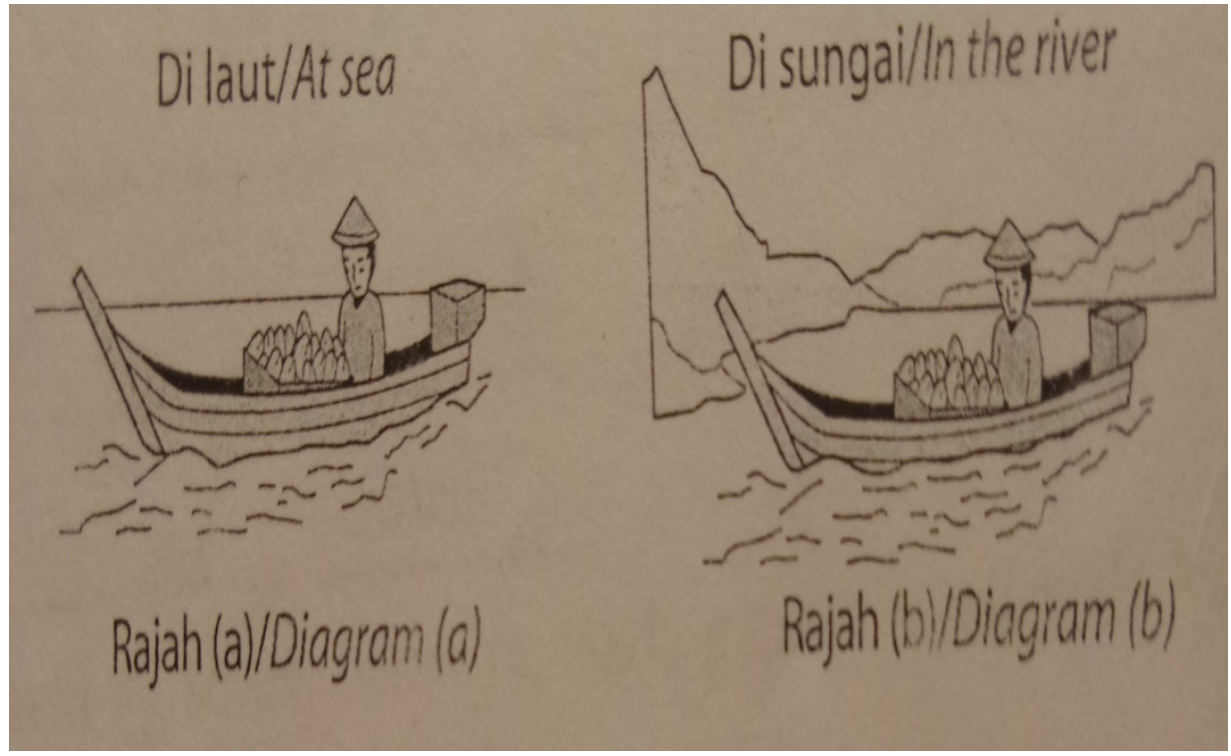

Figure 5. A Boat and the Buoyancy Phenomenon.

[Data source: Maryam, 24 ${ }^{\text {th }}$ August 2015]

Incorporating real-world applications of physics such as the ships and boats in the Archimedes' principle learning was particularly relevant to show students the significance of a physics concept in the actual life.

\subsection{Use of Design Activities}

Only one teacher, Aliah, conducted a design activity whereby she asked students to design a tangible model of pressure in liquid using low-cost materials. Students were asked to creatively make holes on the bottle to show the influence of height to the pressure of water. 


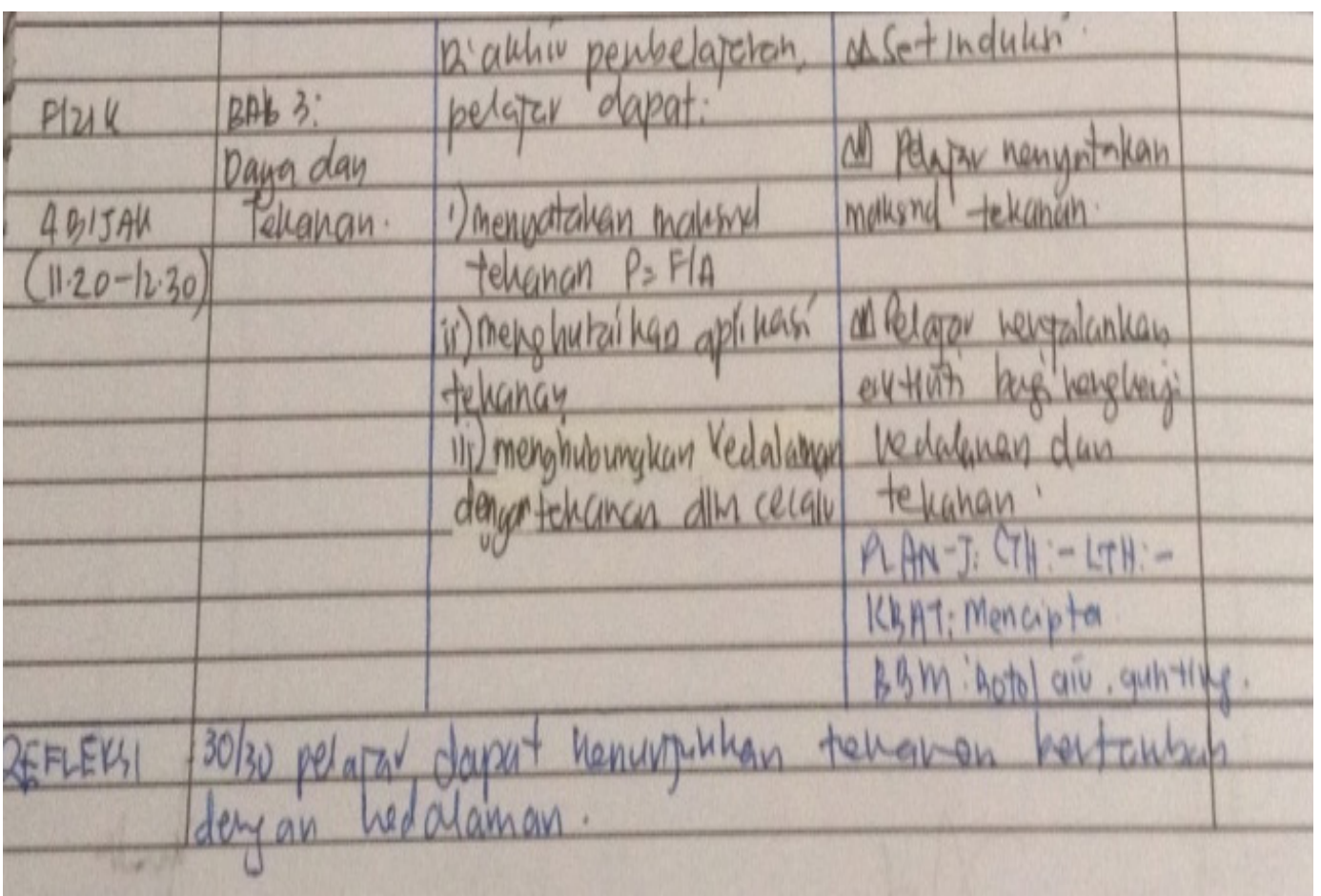

Figure 6. The Lesson Plan Regarding the Design Activity.

[Data source: Aliah, $6^{\text {th }}$ July 2015]

In the lesson plan that Aliah made (Figure 6), she wrote the word of "mencipta" or in English is called "creating." The design activity required the students to create the model of pressure in liquid.

In relation to the design activity, Aliah realized that time was not sufficient for her to lengthen the activity in order for students to complete and improve their work. She said during the class that: "Have you done design your models? Any group that has finished can present the model first. Please, we did not have enough time. You will need to present your models and compete with other groups" [Data source: Voice records, $6^{\text {th }}$ July 2015].

\subsection{Subject Integration}

For the element of subject integration, all teachers believed in the importance of incorporating real-world applications in physics as a way to integrate science with other subjects. They really taught students applications of physics concepts. For Yusof, he stated that, "Physics is one of the branches of science. Science has chemistry, biology and physics. Physics is closely connected to STEM because it includes technologies, inventions, and innovations that require students to think" [Data source: Post-teaching interview, $26^{\text {th }}$ August 2015]. Yusof taught students applications such as ships when teaching Archimedes' principle (see Figure 3) and other applications such as vacuum cleaners (atmospheric pressure) and hydraulic jacks (Pascal's principle).

For Aliah, she described that, "Kids are like little engineers. They like to modify objects such as changing their bicycles' design. We need more of this kind of kids to make learning more concrete by allowing them to apply physics concepts in real-world applications" [Data source: Post-teaching interview, 22 ${ }^{\text {nd }}$ August 2015]. When teaching topics such as Archimedes' principle, Aliah taught students the applications such as ships (see Figure 4) and other applications such as dams (pressure in liquid) and Bourdon gauges (atmospheric pressure).

For Maryam, she mentioned that, "I see that physics has many technological applications such as the use of telescope in the topic of Light. I feel that STEM could be applied in many physics topics" [Data source: Post-teaching interview, $2^{\text {nd }}$ September 2015]. Maryam taught students applications such as boats (see Figure 5) and other applications such as aeroplanes (Bernoulli's principle) and siphons (atmospheric pressure).

Overall, the teachers tended to view the integration of science with other STEM subjects as incorporation of real-world applications in physics learning because those actual applications could mainly cover engineering and technology elements. The teachers inclined to view engineering and technology as the applications of science concepts, such as Bernoulli's principle that is applied to design aeroplanes.

\subsection{Group Work and Communication}

Two teachers, Aliah and Maryam practiced teaching that encouraged student teamwork and communication through 
group-based learning. The element was not evident in Yusof's teaching. Aliah asked students to work in groups for design activities (for the pressure in liquid topic) and asked students to make group presentation when teaching the topic of atmospheric and gas pressure. One example is provided.

Students were divided into several groups for a group activity. They were provided with posters and marker pens. There were six (6) groups formed. The teacher asked students to give explanations and to do group presentations. This activity was consistent with one of STEM features, teamwork and communication. Each group needed to choose and present only one application of atmospheric and gas pressure, namely siphon, vacuum cleaner, drinking straw, crushed can, plastic hook and Magdeburg sphere.

[Data source: Observation notes, $14^{\text {th }}$ July 2015]

For Maryam, she asked students to do laboratory work in groups and make group discussion when teaching the topic of Archimedes' principle.

When you measure the weight of the object (loads) in air and water, they were different in magnitudes. Why did this happen? Please answer my question and rationalize your answer. Each group needs to discuss the question. I want only one answer for each group. You need to write down your answers on the whiteboard.

[Data source: Voice records, $17^{\text {th }}$ August 2015]

From Aliah's and Maryam's practices of teaching, teamwork and communication could be applied through in-group design activities, student presentations, and in-group laboratory work and discussion. These various approaches of teaching have provided the students opportunities to exchange ideas and communicate with peers.

\section{Discussion and Implications}

Overall, the descriptions on the physics teachers' teaching practice have indicated that the teachers have a relatively accurate concept of integrated STEM. However, their actual teaching practice in classrooms did not totally align with their thoughts, especially when all of them believed that teaching of physics and STEM should be student-centred, but in real practice, they still use teacher-centred pedagogy. Traditionally, Malaysian science teachers have practiced teacher-centred approaches (Thomas \& Watters, 2015). This established teaching practice seems to prevail in schools. In this regard, the teachers' thinking regarding teaching and their real teaching practice did not align. Even though some of the physics teachers practiced group discussion and group-based lab work, this practice of teaching needs to be enhanced because it was still in the large control by the teachers such as one teacher asked students to do lab work according to the teacher's specific instructions. This type of "cookbook" lab work is the practice of many science teachers around the globe (Hofstein \& Kind, 2012). The implication to integrated STEM teaching is that physics teachers need to be assisted to translate their thinking of teaching into actual teaching. This translation is to ensure that they really can work on one critical feature of integrated STEM teaching, use of student-centred pedagogy. Translating integrated STEM teaching ideas into real practice of teaching is proven challenging and scholars (Czerniak \& Johnson, 2014; Stohlmann et al., 2011; Wang, 2012) acknowledged it. Therefore, a systematic training is required to ensure the goal of STEM education stated in the Malaysia Education Blueprint 2013-2025 (Ministry of Education, 2013) to improve STEM education is achievable.

Another point is that all teachers tended to value the importance of incorporating real-world applications of physics as the means to connect physics with technology, engineering and mathematics. They really covered the physics applications in their teaching. In relation to integrated STEM teaching, inclusion of meaningful and engaging contexts of learning is central. Nonetheless, the teachers' teaching practice appear to use the routine-type of solving problems regarding physics applications. This means they use written questions of physics as the means to teach students about the real-world applications. Integrated STEM teaching requires teachers to not simply use routine problem-solving activities. Instead, teachers are required to provide students with real-world problems from the surrounding and students are to solve those complex problems. This would enhance students' critical thinking and creativity.

In addition to the value of incorporating real-world applications of physics, this element might be able to integrate various STEM subjects, science, technology, engineering, and mathematics. For example, a teacher, Yusof, believed that physics has a close connection with STEM. Yusof's thought aligned with the literature (Kertil \& Gurel, 2016; Kim et al., 2015). Yusof mentioned about inventions and innovations that are tightly connected to STEM. Inventing and innovating solutions go through an engineering design process. However, not all physics teachers adopted design activities except for Aliah, but Aliah's activity of design was rather simple and less challenging. The implication to integrated STEM teaching is that teachers should be trained to use engineering design as one pedagogy to be used in classrooms. Engineering design is likely to integrate each STEM discipline because students need to apply their knowledge of physics, technology, engineering and mathematics to invent or innovate solutions to real-world problems.

Regarding teamwork and communication, they might be realized in engineering design process and/or scientific inquiry. Two teachers used group-based learning as the means to promote communication and collaboration. This 
practice should be continued in the future because it aligns with the integrated STEM teaching.

\section{Suggestions for Future Research and Limitation of the Study}

For future studies, we would like to suggest scholars to further investigate a critical question, how to implement effective integrated STEM teaching in actual classrooms? This question is central to help teachers to get concrete guides for integrated STEM teaching in real practice.

This study was limited in terms of the small number of participants. For future studies, more teachers could be included to give a better picture of current status of physics teaching in school contexts in relation to integrated STEM teaching. Probably, scholars could also include mathematics, technology, and engineering teachers to enrich perspectives of integrated STEM teaching because STEM disciplines are wide and not only for physics.

\section{Acknowledgements}

We would like to thanks Universiti Teknologi Malaysia (UTM) for the research grant provided under the project of grant number of PY/2019/00415, the Research University Grant.

\section{REFERENCES}

[1] Bryan, L., Moore, T., Johnson, C., \& Roehrig, G. (2016). Integrated STEM education. In C. Johnson, E. Peters-Burton, \& T. Moore (Eds.), STEM road map: a framework for integrated STEM education (pp. 23-37). New York, NY: Routledge.

[2] Bunyamin, M. A. H., \& Finley, F. (2016). STEM education in Malaysia: Reviewing the current physics curriculum. Paper presented at the International Conference of the Association for Science Teacher Education, Reno, NV.

[3] Bybee, R. (2013). The case for STEM education: Challenges and opportunities. USA: NSTA Press.

[4] Creswell, J. W. (2013). Qualitative inquiry \& research design: Choosing among five approaches. Thousand Oaks, CA: Sage Publications, Inc.

[5] Czerniak, C. M., \& Johnson, C. C. (2014). Interdisciplinary science teaching. In N. G. Lederman, \& S. K. Abell (Eds.), Handbook of research on science education (pp. 395-411). New York, NY: Routledge.

[6] Duit, R., Schecker, H., Hottecke, D., \& Niedderer, H. (2014). Teaching physics. In N. G. Lederman, \& S. K. Abell (Eds.), Handbook of research on science teaching (pp. 434-456). New York, NY: Routledge.

[7] Hofstein, A., \& Kind, P. (2012). Learning in and from science laboratories. In B. J. Fraser, K. G. Tobin, \& C. J. McRobbie (Eds.), Second international handbook of science education (pp. 189-207). Dordrecht, the Netherlands: Springer.

[8] Jayarajah, K., Saat, R. M., \& Rauf, R. A. A. (2014). A review of science, technology, engineering \& mathematics (STEM) education research from 1999-2013: A Malaysian perspective. Eurasia Journal of Mathematics, Science \& Technology Education, 10, 155-163.

[9] Kertil, M., \& Gurel, C. (2016). Mathematical modeling: a bridge to STEM education. International Journal of Education in Mathematics, Science and Technology, 4(1), 44-55.

[10] Kim, C., Kim, D., Yuan, J., Hill, R. B., Doshi, P., \& Thai, C. N. (2015). Robotics to promote elementary education pre-service teachers' STEM engagement, learning, and teaching. Computers and Education, 91, 14-31.

[11] Kloser, M., Wilsey, M., Twohy, K. E., Immonen, A. D., \& Navotas, A. C. (2018). "We do STEM": unsettled conceptions of STEM education in middle school STEM classrooms. School Science and Mathematics, 118(8), 335-347.

[12] Merriam, S. B. (1998). Qualitative research and case study applications in education: Revised and expanded from case study Research in education. San Francisco, CA: John Wiley \& Sons.

[13] Ministry of Education. (2013). Malaysia education blueprint 2013-2025 (Pre-School to post-secondary education). Putrajaya: Ministry of Education.

[14] Ministry of Education. (2005). Integrated curriculum for secondary schools: Curriculum specification of Form Four Physics. Putrajaya: Ministry of Education.

[15] Moore, T. J., Johnson, C. C., Peters-Burton, E. E., \& Guzey, S. S. (2016). The need for a STEM road map. In C. C. Johnson, E. E. Peters-Burton, \& T. J. Moore (Eds.), STEM road map: A framework for integrated STEM education (pp. 3-12). New York, NY: Routledge.

[16] Patton, M. Q. (2002). Qualitative research \& evaluation methods (3rd ed.). Thousand Oaks, CA: SAGE Publications.

[17] Roehrig, G. H., Moore, T. J., Wang, H. -H., \& Park, M. S. (2012). Is adding the E enough? Investigating the impact of K-12 engineering standards on the implementation of STEM integration. School Science and Mathematics, 112, $31-44$

[18] Rubin, H. J., \& Rubin, I. S. (2012). Qualitative interviewing: The art of hearing data (3rd ed.). Thousand Oaks, CA: SAGE Publications.

[19] Saldana, J. (2013). The coding manual for qualitative researchers $\left(2^{\text {nd }}\right.$. Ed.). Thousand Oaks, CA: Sage Publications.

[20] Siew, N. M., Amir, N., \& Chong, C. L. (2015). The perceptions of pre-service and in-service teachers regarding a project-based STEM approach to teaching science. SpringerPlus, 4, 1-20.

[21] Srikoom, W., Hanuscin, D. L., \& Faikhamta, C. (2017). Perceptions of in-service teachers toward teaching STEM in 
Thailand. Asia-Pacific Forum on Science Learning and Teaching, 18(2), 1-23.

[22] Stohlmann, M., Moore, T. J., McClelland, J., \& Roehrig, G. H. (2011). Impressions of a middle grades STEM integration program: Educators share lessons learned from the implementation of a middle grades STEM curriculum model. Middle School Journal, 43(1), 32-40.

[23] Thomas, B., \& Watters, J. J. (2015). Perspectives on Australian, Indian and Malaysian approaches to STEM education. International Journal of Educational Development, $45,42-53$.

[24] Wang, H. -H. (2012). A new era of science education: Science teachers' perceptions and classroom practices of science, technology, engineering, and mathematics (STEM) integration (PhD's dissertation). Retrieved from the University of Minnesota Digital Conservancy, http://hdl.handle.net/11299/120980. 